See Article page 121

\section{Commentary: Full-service salvage operation}

\author{
Reilly D. Hobbs, MD, and Ming-Sing Si, MD
}

The primary goal in the treatment of acute aortic syndromes such as dissection and rupture is to produce survivors. Only after survival is reasonably assured should attention be given to treating concomitant disease that is not immediately life-threatening. However, in the acute period of presentation and treatment, delineating between immediately life-threatening and not immediately life-threatening lesions is not always clear. Aortic coarctation accounts for $6 \%-8 \%$ of all congenital heart disease and is associated with bicuspid aortic valve defects, ventricular and atrial septal defects, and patent ductus arteriosus. Aortic coarctation is most often diagnosed in infancy or early childhood, but mild forms of the disease may not present until later in life. Unrepaired aortic coarctation can lead to aortic aneurysm and/or dissection, ventricular dysfunction, coronary artery disease, and stroke. ${ }^{1}$

Recommendations from the European Society of Cardiology and the American Heart Association/American College of Cardiology state that coarctation repair is indicated in all adult patients with a $>20 \mathrm{~mm} \mathrm{Hg}$ pressure difference between the upper and lower extremities and hypertension $(>140 / 90 \mathrm{~mm} \mathrm{Hg}$ ), severe elevations in blood pressure in response to exercise, or left ventricular hypertrophy. Regardless of pressure gradient, patients with $>50 \%$ aortic narrowing also should be considered for treatment. ${ }^{2,3}$ Traditionally, surgical repair has been the treatment of choice for coarctations in patients of all ages; however,

From Section of Pediatric Cardiovascular Surgery, Department of Cardiac Surgery, University of Michigan, Ann Arbor, Mich

Disclosure: The authors reported no conflicts of interest.

The Journal policy requires editors and reviewers to disclose conflicts of interest and to decline handling or reviewing manuscripts for which they may have a conflict of interest. The editors and reviewers of this article have no conflicts of interest.

Received for publication March 26, 2020; revisions received March 26, 2020; accepted for publication March 27, 2020; available ahead of print April 6, 2020.

Address for reprints: Ming-Sing Si, MD, 11-735 CS Mott Children's Hospital SPC 4204, 1540 E. Hospital Drive, Ann Arbor, MI 48109-4204 (E-mail: mingsing@ umich.edu).

JTCVS Techniques 2020;2:126-7

2666-2507

Copyright $@ 2020$ The Authors. Published by Elsevier Inc. on behalf of The American Association for Thoracic Surgery. This is an open access article under the CC BY-NCND license (http://creativecommons.org/licenses/by-nc-nd/4.0/).

https://doi.org/10.1016/j.xjtc.2020.03.030

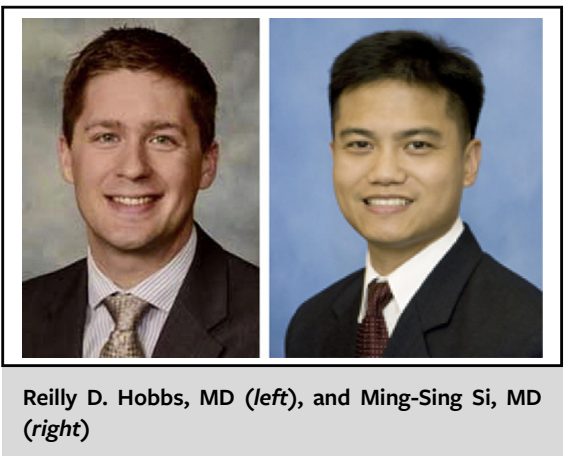

CENTRAL MESSAGE

During salvage scenarios, it is okay to leave residual lesions that can later be addressed electively.

transcatheter therapy has become the treatment of choice for patients weighing $>25 \mathrm{~kg}$. ${ }^{4,5}$

Mihalj and colleagues ${ }^{6}$ should be congratulated on their management of a complicated case of a contained ascending aortic rupture in a young man with concomitant aortic root/ ascending aneurysm, bicuspid aortic valve, and aortic coarctation. Emergent surgical repair of the aortic rupture and aneurysm is clearly indicated; however, the optimal treatment of a coarctation in this scenario deserves consideration. The authors were faced with choosing between treating the coarctation in the emergent setting or providing expectant management with elective TEVAR postoperatively. In the setting of emergent proximal aortic surgery, a chronic coarctation that is well collateralized with minimal gradients should be managed expectantly. The added morbidity of circulatory arrest, arch reconstruction, and/or deployment of a frozen elephant trunk is clearly not indicated in a hemodynamically insignificant coarctation. Urgent surgical repair should be considered only in the presence of severe left ventricular dysfunction or end-organ dysfunction secondary to malperfusion from the coarctation.

The management of this young man with undiagnosed coarctation and an acute aortic syndrome highlights the importance of a multidisciplinary approach to aortic pathology along with the merits of managing non-life-threatening concomitant pathology conservatively. It is important for surgeons to remain up to date on evolving treatment options as indications and capability of transcatheter therapies continues to expand.

\section{References}

1. Law MA, Tivakaran VS. Coarctation of the Aorta. Treasure Island, FL: StatPearls Publishing; 2020. 
2. Stout KK, Daniels CJ, Aboulhosn JA, Bozkurt B, Broberg CS, Colman JM, et al. 2018 AHA/ACC guideline for the management of adults with congenital heart disease. Executive summary: a report of the American College of Cardiology/American Heart Association task force on clinical practice guidelines. Circulation. 2019;139:e637-97.

3. Baumgartner H, Bonhoeffer P, De Groot NM, de Haan F, Deanfield JE, Galie N, et al. ESC guidelines for the management of grown-up congenital heart disease (new version 2010). Eur Heart J. 2010;31:2915-57.
4. Lala S, Scali ST, Feezor RJ, Chandrekashar S, Giles KA, Fatima J, et al. Outcomes of thoracic endovascular aortic repair in adult coarctation patients. J Vasc Surg. 2018;67:369-81.e2.

5. Correction: diagnosis, imaging and clinical management of aortic coarctation Heart. 2019;105:e6.

6. Mihalj M, Makaloski V, Hurni S, Friess J-O, Melis C, Carrel TP, et al. A young marathon runner with severe aortic coarctation and bicuspid aortic valve disease complicated by contained aortic rupture. J Thorac Cardiovasc Surg Tech. 2020;2:121-3. 